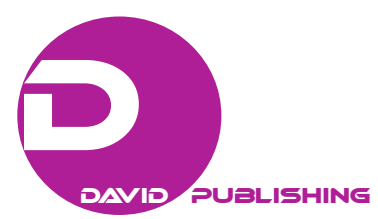

\title{
Russian M\&A Market: Dynamics and Current State
}

\author{
Larissa Lugacheva \\ Siberian Branch of Russian Academy of Science, Novosibirsk, Russia \\ Maria Musatova \\ Novosibirsk National Research State University, Novosibirsk, Russia
}

\begin{abstract}
We identify five phases in the formation of M\&A from the beginning until the newest developments when economic sanctions were imposed. The paper summarizes the results of empirical analysis of mergers and acquisitions (M\&A) of Russian companies over the period 1995-2013. To capture the time series behaviour of M\&A processes, we fit an autoregressive integrated moving average (ARIMA) model. We further analysed co-integration of M\&A processes in Russia and US, China, and Germany. The results indicate German and Chinese M\&A series have a long-term influence on Russian series, while no significant causal links were evidenced in the dataset between US and Russian series.
\end{abstract}

Keywords: mergers and acquisitions, cross-border deals, ARIMA, cointegration

\section{Introduction}

Formation of the Russian market for corporate control occurred against the backdrop of the fifth global wave of mergers and acquisitions (M\&A) (1994 to 2000), which was characterized by the appearance of mega deals, intensified participation of European market players, consolidation of exchanges in Europe, internationalism, and boom of foreign direct investment in the country.

In the sixth wave of global M\&A, Russia shared similar features of the market for corporate control to the developed countries of Europe. These features were as follows: availability of low-interest financing, promotion of creation of giant groups of companies, changes in legal regulation, strong competition, high activity of investment funds, the trend towards consolidation of assets in many industries, stock exchange consolidation and consolidation in the banking sector. At the same time, the financial and banking sectors were the main areas of regulation and state inspections. Currently, the top sectors in terms of M\&A activity in Russia with the largest transactions are energy, oil \& gas, and telecommunications.

The paper contributes in several areas. We identify five phases in the formation of M\&A from the beginning until the newest developments when economic sanctions were imposed. The paper summarizes the results of empirical analysis of mergers and acquisitions (M\&A) of Russian companies over the period 1995-2013. To capture the time series behaviour of M\&A processes, we fit an autoregressive integrated moving

Larissa Lugacheva, Ph.D., lead research fellow, associate professor, Institute of Economics and Industrial Engineering, Siberian Branch of Russian Academy of Science, Novosibirsk, Russia.

Maria Musatova, Ph.D., senior research fellow, associate professor, Novosibirsk National Research State University, Novosibirsk, Russia.

Correspondence concerning this article should be addressed to Larissa Lugacheva, Institute of Economics and Industrial Engineering, Siberian Branch of Russian Academy of Science, Novosibirsk, Pr. Lavrentieva 17, 630090, Russia. 
average (ARIMA) model. We further analysed co-integration of M\&A processes in Russia and US, China, and Germany.

\section{Phases of the Russian M\&A Market}

The main feature that distinguishes the Russian M\&A market from the markets of developed countries against this background is rapid evolution from small local transactions to large-scale cross-border mergers and acquisitions: In the period 1999-2007, the M\&A market in Russia grew by more than 30 times.

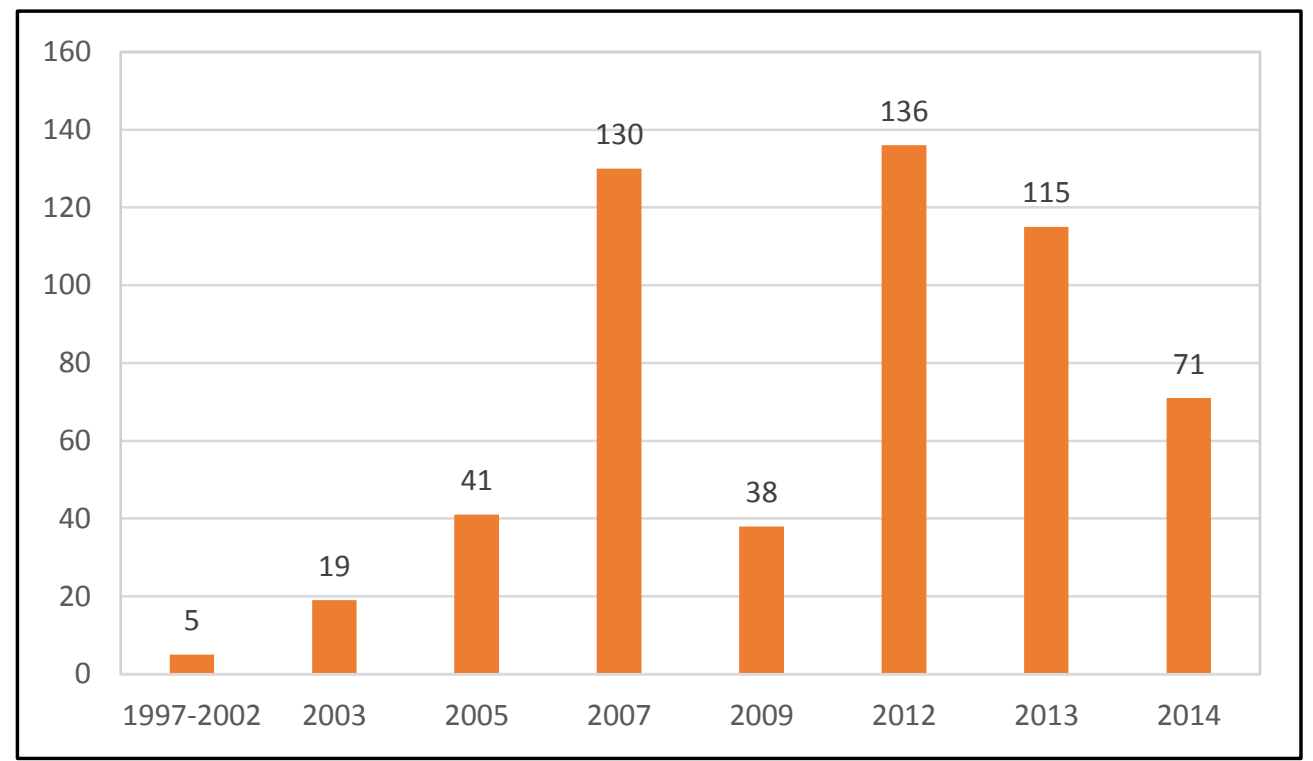

Figure 1. Volume of the Russian M\&A market (in \$ bln), except for 1997-2002 where it is an average deal size (KPMG, 2014).

We distinguish the following five stages of evolution of the market of mergers and acquisitions in Russia (Musatova, 2006):

The first phase (1993-1998) relates mainly to the liberalization of markets, mass privatization of state-owned assets, with many acquisitions taking place via the privatisation route. This method was relevant as an independent mechanism, and as part of the expansion strategy of the first financial-industrial groups (a majority of them had an informal structure and originated in the banking sector). In conditions when the market institutions were quite nascent, the primary rationale for integration was the desire for stability of the business linkages necessary for companies' survival. It was not so much the goal of businesses to create value and increase shareholder's wealth yet, rather to assemble and unify the shareholders capital, to transfer and assert the controlling stakes in the process of transformation of ownership. At the end of this period, the number of M\&A transactions is on the rise, while at the same time their transparency is declining. The proportion of companies acquired via bankruptcy procedure has increased.

The second stage, the "post-crisis boom" of 1999-2002, was associated with the redistribution of property (assets) after the 1998 crisis. It was predominantly characterized by a significant rise in hostile takeovers and a high proportion of "speculative" M\&A transactions in the total volume of the market. A number of companies, including large corporates, fell victims to the 1998 financial crisis and were going through difficult times. It is during this stage that a large-scale application of corporate raids, greenmail, and hostile takeover practices had 
begun; these activities exploited the gaps in the legislation covering the activities of firms and wide-spread corruption of the administrative apparatus. According to PwC, in 2001 Russian deals had become the main driving force of the M\&A market in the Central and Eastern Europe. The Russian market for corporate control gained momentum with 237 deals, drawing in a growing number of participants, and involving huge financial resources (Expert, 2012).

Starting in this period, cross-border transactions of Russian companies were on the rise, which was largely associated with the achievement of relative political stability in the country and improvements in the investment climate.

The third stage in the evolution of M\&A processes occurred during the economic growth of 2003-2008. By this time, most existing corporates had completed their expansion strategies and financial-industrial groups were now at the stage of aligning their assets into vertically integrated structures and divesting non-core assets. It is at this time that government-owned banks and corporates come to the forefront of the M\&A market. Further, the third stage of M\&A processes is characterised by an increased share of transactions conforming to standards (according to modern norms) and use of transparent mechanisms for restructuring of assets, including public capital markets. Another important milestone in the establishment of the M\&A market took place in this period, with five megadeals recorded in 2005, when the first megadeal was recorded - the purchase by Gazprom of the $73 \%$ stake in Sibneft for $\$ 13.1$ bln. In that year, the dollar amount of transactions more than doubled to 40.5 billion dollars as compared to 2004 , and domestic transactions began gaining momentum. Until 2005, the Russian M\&A market was in a nascent stage: the volume of deals in the period from 1997 to 2002 averaged about $\$ 5.0$ bln per year (KPMG, 2014).

The fourth stage in M\&A development is associated with the onset of the global financial crisis in 2008, and decline in the number and valuation of M\&A in the country. The reduction in the number of international mergers and acquisitions in Russia was not only due to the financial crisis, restricting the financial ability of Russian companies, but also due to serious risks associated with asset purchases in developed countries (strong competition, difficulties in managing multinational business and integrating acquired assets, lack of experience about the markets of developed countries).

The fifth stage is taking place presently and reflects the M\&A market in recession vis-à-vis international sanctions. The fifth stage reflects a shift in the direction of cross-border transactions; the closure of a number of international programs for creation of joint ventures in the second half of 2014 due to the third wave of sanctions, and lastly, a further strengthening role of the state. Furthermore, companies that were not directly affected by the sanctions were also experiencing the impact of the tensions between Russia and the West. However, some deals still went through. Despite objections from the UK government, Russian fund LetterOne, controlled by billionaire Mr. Fridman, acquired North sea oil and gas fields for EUR 5 bln from RWE Dea.

The data indicates that Russian companies were intensively selling their international assets located in the countries that were party to sanctions. At the same time, the focus of M\&A deals turned eastwards towards the markets in Asia-Pacific region, Latin America, BRICS countries, Commonwealth of Independent States, and the domestic market for corporate control in Russia.

A unique feature of the Russian market of mergers and acquisitions is its strong relationship with processes taking place in the political sphere. Most of those processes involved the political agenda of either the 
local or federal authorities, and frequently this agenda would run counter to the wishes of the shareholders. The state share in the M\&A market is high and some sources estimate it to be no less than $40 \%$, according to Mergers.ru (2011).

However, in both Russian and Western markets, the M\&A activity of players varies depending on market conditions in each sector. At the moment, the most active sectors at the Russian M\&A market are energy, oil, and telecommunications; these are the sectors where most major M\&A transactions take place.

\section{Waves of M\&A and Other Approaches to Model the Series}

Most researchers and practitioners agree that M\&A throughout there is best described as waves of M\&A activity. In particular, throughout the 20th century the dynamics of M\&A occurred in waves.

There are several theoretical approaches explaining the wave-like behaviour of M\&A, industrial economics, financial economics, and behavioural economics. The former defends that strategic synergies between companies is the main motive in corporate expansion. A successful example of M\&A would be a signal for other companies that this strategy could be yielding significant synergies. If many companies in the economy follow the suit, a chain reaction will be triggered, which eventually leads to a wave of M\&A.

From the standpoint of financial economics, the waves of M\&A are one-time reaction of companies to external shocks in the economic environment (e.g., technological shocks and demand shocks). Economic, technological shocks and shocks of government regulation serve as a catalyst in the waves of M\&A (Harford, 2005). Aggregated waves of M\&A can either be caused by a temporary adjustment of the market, or by an industry shock, for which mergers assist companies to adjust to new market conditions. A necessary condition that a particular shock will lead to a wave of mergers is the presence and the amount of liquidity in the market for corporate control. Liquidity in this case is assumed to be the availability of free cash flow, including for potential M\&A transactions.

Testing hypotheses regarding the wavelike behaviour of mergers has attracted attention from researchers for a long time. This area is well covered elsewhere, with plenty of findings reported under each competing theoretical explanation. However, recent developments in explaining M\&A temporal activity aimed at explanation of the process of M\&A using a model with a switching parameter, where the waves of M\&A are triggered by the "switching" of a discrete parameter. The use of Markov processes with switching regime solves the issue of defining the specific time intervals when waves occur (Qiu \& Zhou, 2007; Shen, Chen, \& Lin, 2008; Town, 1992; Harford, 2005; Resende, 1999).

Town offers to model M\&A as a nonlinear process, in which wave-like behaviour is generated endogenously. Qiu and Zhou (2007) and Resende (1999) model the dynamics of M\&A by using nonlinear stochastic processes, and suggest that it is not a given that M\&A activity occurs in waves, rather there are periods of high and low activity. The dynamics of M\&A is interspersed with periods of high average and high standard deviation and periods with low average and low standard deviation. Therefore, the authors conclude that the dynamics of M\&A as one-dimensional event are considered an endogenous process.

Barkoulas, Baum, and Chakraborty (2001) considered that the observed nonperiodic cycle of M\&A may be associated with the presence of long-term memory in the process. Therefore, such processes can be predicted over a long period of time. Barkoulas employed the data on American transactions and showed that M\&A process has long-term dependence, and therefore, the impact of shocks on M\&A will fade more slowly. Fluctuations in M\&A are affected not only by its immediate history, but also by the values of M\&A in the 
distant past. This behavior of integration processes indicates the presence of fundamental factors affecting the dynamics of the series.

In Russia, the earliest study of corporate integration was conducted by Ignatishin, who calculated correlations between M\&A data at hand and a set of macroeconomic variables including inflation, oil prices, RUB/EUR and RUB/USD exchange rates, capitalisation of RTS index, etc.

Musatova (2006) further considered the relationship between macro variables and dynamics of M\&A. While the sample covering 2001-2004 included more than 2,500 transactions, there were not enough years in the available databases to analyse quarterly data points. At the same time, specifics of the Russian M\&A market at the time suggested that legal structuring and completion of the transaction took less time by far than in the West. With just 48 observations, Musatova estimated Poisson regression for the number of M\&A deals. The model was augmented by trend and seasonality components, and explanatory variables contributed to explaining $79 \%$ of the dynamics of transactions for the period. Inverse relationships for the M\&A series were found to be statistically significant for the growth rate of real industrial production (lagged), volatility of the RTS index, and the share of unprofitable enterprises in the total number of industry organizations. Statistically significant and positive relationship was found for the net financial results of the main sectors of the economy.

Polikaropova (2011) further describes the intensity of M\&A processes and their linkages with macroeconomic indicators for 2004-2010. The analysis takes into account specifics of the M\&A in that timeframe - hostile nature of the deals, corporate raids, abuse of procedural rights in the course of corporate conflicts. Polikarpova considers three endogenous variables: monthly data on the number of deals, the volume of deals, and the valuation of assets that are party to corporate conflicts. The analysis indicated an inverse relationship between stock market volatility and dollar volume of the M\&A market: The growing uncertainty on the capital market will discourage the enterprises to carry out innovation and investment projects, including M\&A transactions. This result corroborates earlier findings for the monthly M\&A data (Musatova, 2006).

\section{Temporal Behaviour of M\&A Processes}

In countries with a developed institutional environment, analysis of the time series of corporate M\&A deals is largely based on econometric approaches. However, given insufficient data history of M\&A series in Russia, methodology to estimate the intensity and linkages of M\&A are just beginning to take shape in the country. Only in recent years, thanks to accumulated consistent M\&A records for over 15 years, time series econometric analysis has become possible.

We use two information databases to analyse the behaviour of Russian M\&A series, Zephyr by Bureau van Dijk and Thompson Financial. We use quarterly data in the analysis.

To analyse time series behaviour of M\&A processes in Russia, we relied on the Thomson Financial resources, which provide an excellent coverage of M\&A since 1995 (although the first deals were recorded as early as 1992, there are only 27 domestic deals for the 1992-1994 period). The data takes into account domestic and cross-border transactions, and we cover the time period until 2013. Overall, we have 76 quarterly observations to work with.

With a growing number of Russian transactions in the global M\&A market in the sixth global wave, their multidirectional character demanded a detailed consideration of the total quantity of Russian M\&A, divided into three components: domestic, import, and export transactions. Outward cross-border M\&A, where a Russian acquirer is involved in a deal with a foreign-based target, are categorized as export M\&A. In the case 
of Russian company being the target in a transaction initiated by a foreign-based acquirer, these transactions are referred to as import M\&A. Further, we distinguish consolidation vs. conglomeration in domestic transactions based on SIC codes. If the SIC codes of the acquiring company and target company match, the transaction can either be vertical or horizontal integration, hence we classify it as domestic consolidation. Similarly, if SIC codes are different, the transaction is likely to be diversifying in nature, hence we classify it as domestic conglomeration. Descriptive statistics for these M\&A series are reported in Table 1.

Table 1

Descriptive Statistics for the M\&A Series, 1995 q1-2013 q4

\begin{tabular}{llll}
\hline M\&A series & Number of transactions & Mean & St. Dev. \\
\hline Total & 18,167 & 239 & 269.2 \\
Import & 3,014 & 40 & 32.4 \\
Export & 1,062 & 14 & 11.5 \\
Domestic consolidation & 3,036 & 40 & 43 \\
Domestic conglomeration & 11,055 & 145 & 190.4 \\
\hline
\end{tabular}

For all of the time series we classified, there are a good number of observations over the time frame. In 1995, there were only 69 domestic transactions recorded in Russia, and by 2005, this number grows to 221 . Interestingly, a vast majority of transactions took place in domestic conglomeration deals. To better assess the dynamics of the series, Figure 2 displays all processes over the time period.

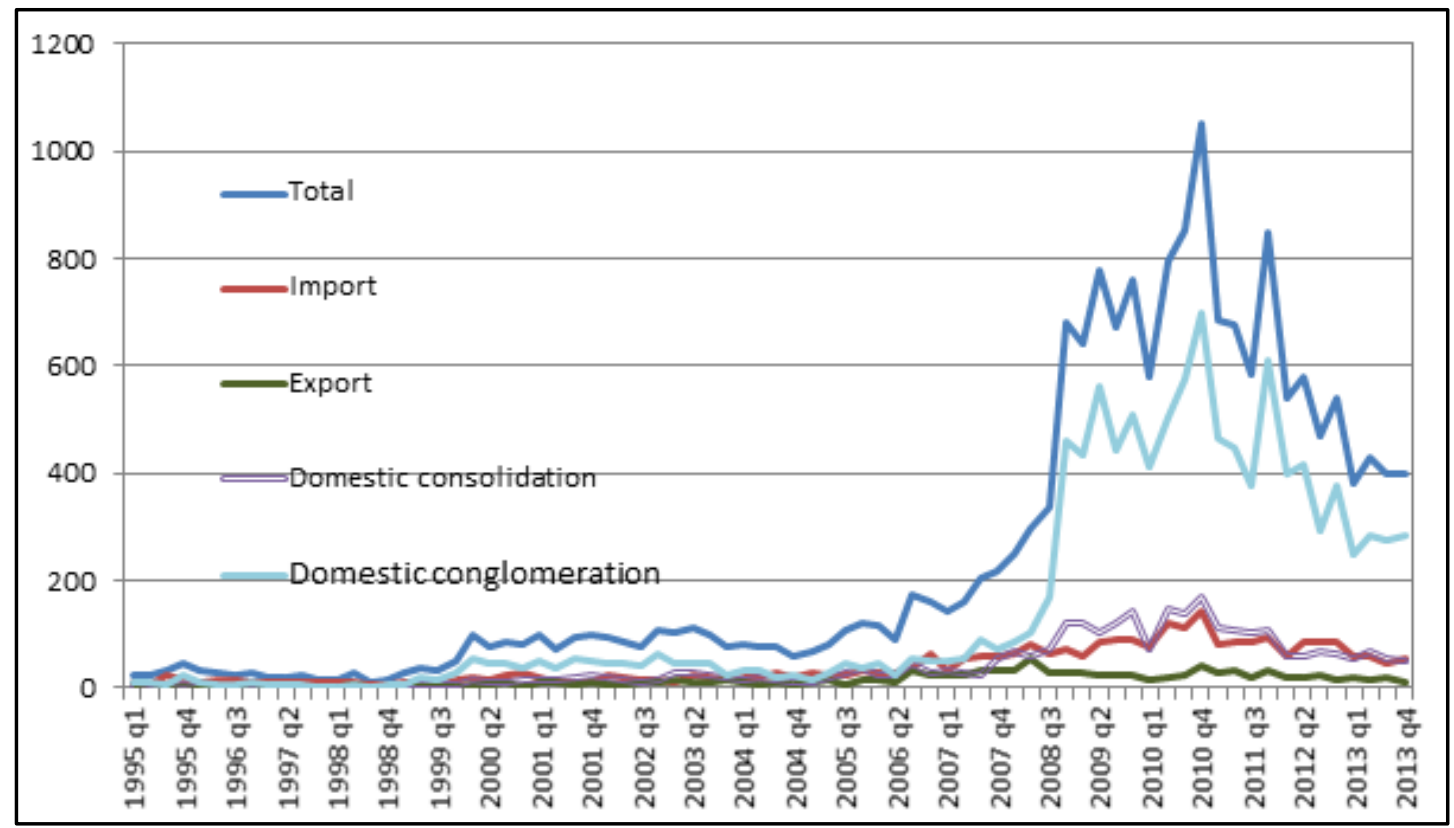

Figure 2. Dynamics of the M\&A series over 1995-2013.

The Figure suggests that in late 2007 or early 2008, the number of domestic conglomeration deals goes up and consequently, the total number of deals sharply goes up and spikes in 2010. At the same time, other time series display consistent behaviour over the entire time frame, with an increase in activity in 2010, though nearly not as pronounced. What we are observing is a structural shift in data, which would require us to make adjustments to the modelling of these series. However, it is important to identify the economic reasons for 
structural shift. Among them we highlight the following four explanations:

1. From a macroeconomic standpoint, 2007 was a peak year in terms of economic growth and high business confidence, which contributed to companies actively pursuing an expansion strategy. M\&A are generally a pro-cyclical variable of economic growth, and it is likely that positive economic background in the early and mid-2007 has created a favourable environment for performing M\&A in subsequent quarters. Together with sustained economic growth, successful integration of Russia into the world community, and increasing transparency of the financial sector during that time, the information space has also improved. This phenomena was reflected in a better disclosure of information by market participants and adequate coverage in the press, both Russian and foreign participants.

2. Increased enterprise debt restructuring via conversion of debt into equity. In the period of economic growth, Russian companies were actively leveraging themselves to build up their production facilities. However, in the crisis period there was a sharp reduction in demand for products manufactured by the enterprises and companies began to have problems servicing debt. In this situation, many banks and corporate creditors preferred to convert the company's debt into equity, rather than to initiate the procedure of bankruptcy. Thus, another explanation for the surge in the number of transactions is the redemption of the shareholders equity by the banks and creditors in their debtors.

3. Accumulated free cash flow during the period of economic growth, and depressed market valuation of companies in a period of instability, served as catalysts for deals. Previous research of Russian M\&A indicated that the prevailing motives for integration at a time of recession tend to be financial and investment motives, as compared to operational and strategic at the times of economic upturn. The sellers of assets were de-risking their balance sheets and cutting down payables, whilst buyers were pursuing potential diversification benefits and seizing potential opportunities due to lower valuations.

4. Strengthening of the role of the state as a party to M\&A transactions. The entrance of the state to the Russian M\&A market began in 2006, and was predicated upon the desire of the state to return its control over strategic enterprises, which was lost during privatization. The state was involved in two very large transactions worth more than $\$ 20$ billion: acquisition of "Sibneft" and increase of its stake to a controlling stake in "Gazprom". Furthermore, with the establishment of state-owned banks and corporations in 2007, participation of the state in M\&A market has been strengthened. By 2008-2009, they became one of the key buyers of any distressed assets.

We smooth the data to account for seasonality components using the Holt-Winters method. However, in order to reflect the presence of a structural shift, we need to account for interventions in the series. To test for the structural shift, we employ the Zivot-Andrews approach to check for the unit root in the each series and calculate the respective t-statistic $\tau=\frac{T_{\mathrm{B}}}{\mathrm{T}}$. The approach identifies the observation with the smallest $\mathrm{t}$-statistic for potential areas where the structural shift is likely to occur. Results are reported in Table 2. We further verified our finding by performing the Chow test for two subsets of each series, where the breaking point was identified by Zivot-Andrews approach.

We then tested M\&A series for presence of long-term memory employing R/S test. With the test, we can identify the time interval, subsequent to which the memory about earlier conditions is lost. $H_{0}$ is that the underlying series is random. Table 3 summarizes the results, which verify no long-term memory in M\&A processes. 
Table 2

Zivot-Andrews Results for Identification of the Structural Shift

\begin{tabular}{lll}
\hline M\&A series & Timing of the structural shift & Zivot-Andrews min. statistic \\
\hline Total & $2 \mathrm{q} 2008$ & -3.696 in observation 54 \\
Import & $3 \mathrm{q} 2007$ & -3.646 in observation 51 \\
Export & $4 \mathrm{q} 2006$ & -3.149 in observation 48 \\
Domestic consolidation & $2 \mathrm{q} 2008$ & -3.126 in observation 54 \\
Domestic conglomeration & $4 \mathrm{q} 2008$ & -5.386 in observation 56 \\
\hline
\end{tabular}

Note. We cannot reject the $H_{0}$ for all series at $5 \%$ significance level.

Table 3

$R / S$ Test Results for Long-Term Memory in M\&A Series

\begin{tabular}{ll}
\hline M\&A series & R/S test statistic \\
\hline Total & 0.82 \\
Import & 1.15 \\
Export & 1.39 \\
Domestic consolidation & 1.15 \\
Domestic conglomeration & 1.22 \\
\hline
\end{tabular}

Note. We cannot reject $H_{0}$ at $1 \%$ as estimated R/S statistic falls into the interval $(0.721 ; 2.098)$.

The series were also tested for stationarity both with Dickey-Fuller and Phillips-Perron tests. The $H_{0}$ is that the series are non-stationary, or contain a unit root. M\&A processes are non-stationary at their levels, but first differencing makes them stationary.

The best fitting model to capture the behaviour of the M\&A activity in Russia is the autoregressive integrated moving average (ARIMA) model with interventions. Given that we are using first differences, we set $\mathrm{d}=1$, and having smoothed the data, we set $\mathrm{q}=0$.

Table 4

Estimated Parameters of ARIMA for the M\&A Series $(N=75)$

\begin{tabular}{|c|c|c|}
\hline M\&A series & Model & Parameters of the model \\
\hline Total & $\begin{array}{l}\text { ARIMA }(5,1,0) \\
\text { intervention at } \\
\text { observation } 54 \\
\text { ARIMA }(4,1,0)\end{array}$ & $\begin{array}{c}\left(1+0.0872 * L+0.0675 * L^{2}+0.0824 L^{3}-0.89291 * L^{4}-0.00674 L^{5}\right)(1-L) x_{t} \\
=\varepsilon_{t}+13.607 * K\end{array}$ \\
\hline Import & $\begin{array}{l}\text { intervention at } \\
\text { observation } 51 \\
\text { ARIMA }(4,1,0)\end{array}$ & $\left(1+0.998 L-0.01551 L^{2}+0.1557 L^{3}-0.10158 L^{4}\right)(1-L) X_{t}=\varepsilon_{t}+11.545 * K$ \\
\hline Export & $\begin{array}{l}\text { intervention at } \\
\text { observation } 48\end{array}$ & $\left(1+0.2201 L+0.0387 L^{2}-0.23895 L^{3}+0.0992 L^{4}\right)(1-L) X_{t}=\varepsilon_{t}+8.6742 * K$ \\
\hline $\begin{array}{l}\text { Domestic } \\
\text { consolidation }\end{array}$ & $\begin{array}{l}\text { ARIMA }(4,1,0) \\
\text { intervention at } \\
\text { observation } 56\end{array}$ & $\left(1+0.0521 L-0.10529 L^{2}-0.04686 L^{3}-0.28015 L^{4}\right)(1-L) X_{t}=\varepsilon_{t}+5.7465 * K$ \\
\hline $\begin{array}{l}\text { Domestic } \\
\text { conglomeration }\end{array}$ & $\begin{array}{l}\text { ARIMA }(5,1,0) \\
\text { intervention at } \\
\text { observation } 54\end{array}$ & $\left(1-0.21904 L-0.1834 L^{2}+0.3061 L^{3}-0.31086 L^{4}\right)(1-L) X_{t}=\varepsilon_{t}+47.415 * K$ \\
\hline
\end{tabular}

For the majority of M\&A processes, our analysis revealed that the fourth lag is positively associated with the dynamics of the dependent variable and contributes to the explanation of the process. The findings suggest 
that the quarterly values of the M\&A are positively associated with the quarterly values in the previous year. The presence of such relationship speaks in favour of the hypothesis of cyclical behaviour of the M\&A processes. The next important lag to contribute to the process explanations is the first lag, i.e., the number of transactions in the previous quarter. It can be concluded that the M\&A market is not changing rapidly, unless there are structural changes in the economy. Although for the total M\&A series, the best fit was ARIMA $(5,1,0)$, the contribution of the fifth lag was less than $1 \%$. Overall, we can conclude that ARIMA $(4,1,0)$ is a best fit to describe Russian M\&A series.

We further tested the predictive power of the ARIMA specifications. We used intra-period forecasting for four periods in 2013 (Table 5).

Table 5

\section{1-Year Forecast for the Estimated ARIMA Models}

\begin{tabular}{llll}
\hline Quarter & Forecasted value & Actual value & Difference \\
\hline Total M\&A & & & \\
\hline 2013 q1 & 855 & 721 & 134 \\
2013 q2 & 680 & 578 & 102 \\
2013 q3 & 521 & 455 & 108 \\
2013 q & 529 & & 74 \\
\hline Import M\&A & & 87 & -4 \\
\hline 2013 q1 & 83 & 77 & 7 \\
2013 q2 & 84 & 76 & 6 \\
2013 q3 & 64 & 19 \\
2013 q4 & 82 & & 2 \\
\hline Export M\&A & 83 & 23 & 5 \\
2013 q1 & 17 & 5 \\
2013 q2 & 25 & 19 & 6 \\
2013 q3 & 22 & 17 & 3 \\
2013 q4 & 24 & & 16 \\
\hline Domestic consolidation M\&A & 23 & 74 & -8 \\
2013 q1 & 77 & 55 & -2 \\
2013 q2 & 71 & 71 & 29 \\
2013 q3 & 63 & 36 \\
2013 q4 & 63 & & 75 \\
\hline Domestic conglomeration M\&A & 61 & 373 & 67 \\
\hline 2013 q1 & 402 & 362 & \\
2013 q2 & 398 & 330 & \\
2013 q3 & 405 & & \\
2013 q4 & 388 & & \\
\hline & & & \\
\hline
\end{tabular}

Overall, the forecasts tend to be slightly more optimistic than the original data, however overall they closely follow the series. Naturally, the further away the forecasted quarter is, the less accurate the predicted values of M\&A will be.

To check models for the presence of autocorrelation, we used Durbin-Watson criterion. Heteroscedasticity of residuals was tested via running a regression of residuals on the residuals squared. As Table 6 reports, the ARIMA models do not have autocorrelation or ARCH-effects in the residuals. The linear models we chose describe the M\&A series well. 
Table 6

Durbin-Watson Results and $R^{2}$

\begin{tabular}{lll}
\hline M\&A series & $\mathrm{DW}$ & $\mathrm{R}^{2}$ in the residuals regression \\
\hline Total & 1.83 & 0.001 \\
Import & 1.85 & 0.008 \\
Export & 2.02 & 0.08 \\
Domestic consolidation & 1.75 & 0.000015 \\
Domestic conglomeration & 1.94 & 0.0025 \\
\hline
\end{tabular}

Overall, for each of the M\&A series considered, we fit the best model to reflect the dynamics in the underlying data, and determine the specification of requisite ARIMA model. The series do not indicate presence of the long-term memory, and the model produces reliable forecasts. Despite a shorter than desirable size of the dataset, the results from the various tests indicate that model is applicable for further use.

\section{Linkages of Russian M\&A Processes With German, Chinese, and US M\&A Processes}

Zephyr data covers the period from 2000 to the first quarter of 2016, which gives us 65 quarterly observations to work with. Unfortunately, this is all the data we have and analysis will be limited by the small size of the sample. To analyse co-integration of M\&A at a country level, we combine domestic transactions and outward directed cross-border transactions. In this case, German M\&A include deals completed between two German companies, and deals where a German company acquired a target company located abroad. Notably, the US market is characterized by a cyclic decrease in the number of transactions starting from the third quarter of 2000 until 2003. The series reached a peak of 6,336 deals in the first quarter of 2007, then went on a downward trend until the third quarter of 2009, and rebounded to the level of 2007 by the third quarter of 2014. The Russian series were showing similar upward trending dynamics to the US series from 2002, peaked out slightly later on in the fourth quarter of 2007 with 2107 deals, and bottomed out in the first quarter of 2013. By the time the US market has recovered, the number of the Russian M\&A was still half of what it used to be in 2007. The data also suggests cyclicality with the highest number of deals occurring in the second and fourth quarters. Interestingly, the German series suggest no definitive long-term trends or waves, and there are no major spikes in the data. Between the years 2000-2006, M\&A peak during the fourth quarter, however from 2012 this dynamic changes and the peak number of transactions occurs in the third quarter. As for the Chinese data, M\&A follow an upward trend through to the fourth quarter of 2010 (with 2,620 transactions), followed by a downward trend until the first quarter of 2014. Similar to the other series, the fourth quarter is the popular time to complete $M \& A$ deals.

Similar to the previous analysis of Russian M\&A based on Thompson financial data, we perform the steps to capture Zephyr-sourced time series.

Table 7

Estimated Parameters of ARIMA for the Country-Level M\&A Series

\begin{tabular}{ll}
\hline Country & Specification \\
\hline Germany & $\operatorname{ARIMA}(1,1,1)$ \\
China & $\operatorname{ARIMA}(3,1,1)$ \\
Russia & $\operatorname{ARIMA}(1,1,1)$ \\
USA & $\operatorname{ARIMA}(1,1,0)$ \\
\hline
\end{tabular}




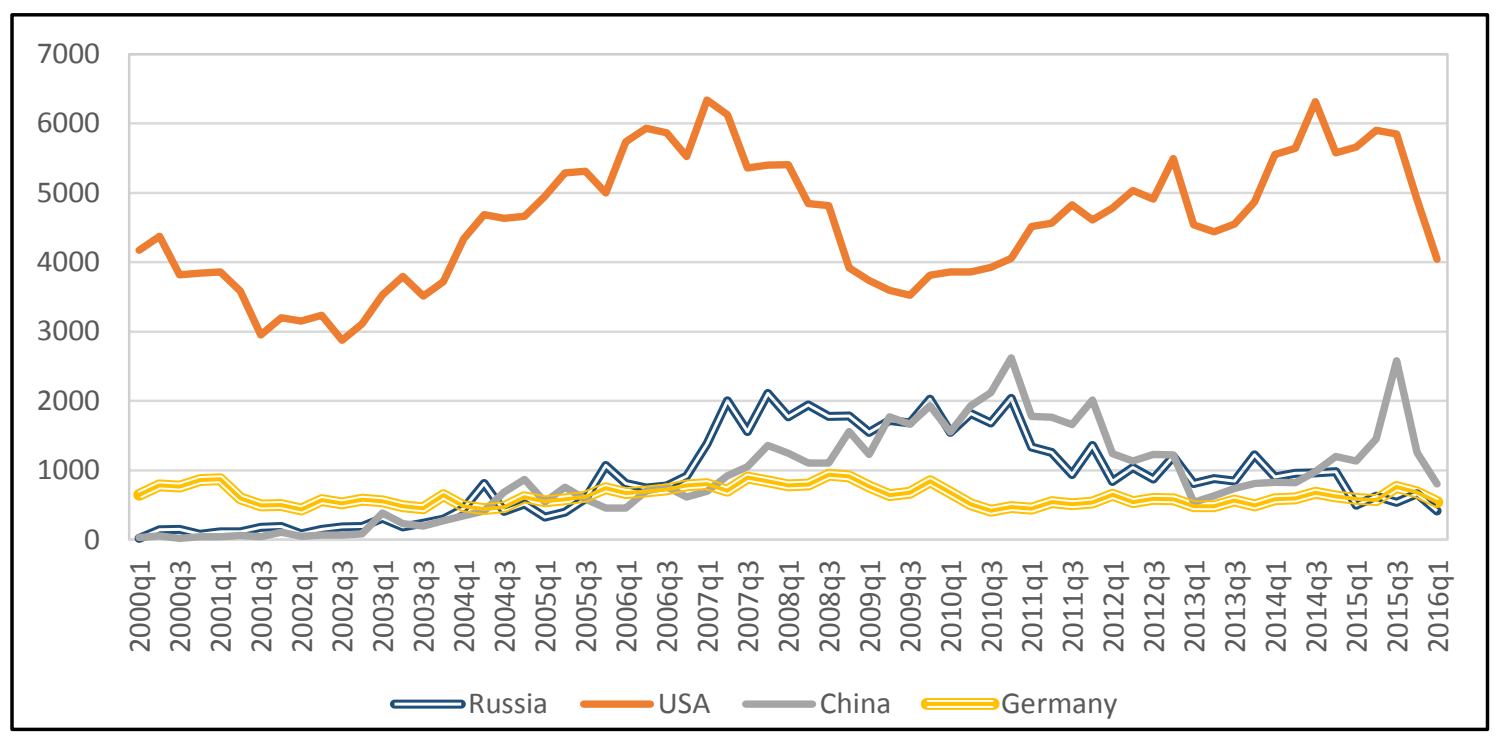

Figure 3. Quarterly dynamics in the number of M\&A deals (Zephyr).

The M\&A series based on Zephyr do not contain a structural shift that we could identify. While ARIMA still is the best model to describe the series, estimated parameters differ.

Granger causality requires that the series have to be covariance stationary, so an augmented Dickey-Fuller test has been calculated (Table 8).

That variables should be integrated to the same order is a requirement of both Granger and Johansen tests for there to be a cointegrating relationship. In our case, all M\&A series being integrated of the same order allows us to carry out both tests.

Table 8

Augmented Dickey-Fuller (ADF) Test Results for Unit Roots

\begin{tabular}{llll}
\hline \multirow{2}{*}{ Country } & Level & \multicolumn{2}{c}{ First differences } \\
\cline { 3 - 4 } & & Intercept & Intercept and trend \\
\hline Germany & $-3.029 * *$ & $-8.777^{* * *}$ & $-8.709 * * *$ \\
China & -2.306 & $-9.902 * * *$ & $-9.885^{* * * *}$ \\
Russia & -1.994 & $-13.037 * * *$ & $-13.326 * * *$ \\
USA & -1.791 & $-7.345^{* *}$ & $-7.297 * *$ \\
\hline
\end{tabular}

Notes. $* * *, * *$ imply significance at $1 \%$ and $5 \%$ level respectively.

Table 8 reports the results of the ADF unit root test for the M\&A series in four countries; all but German M\&A series are non-stationary in their levels and become stationary when they are first differenced.

As a next step to identify the appropriate number of lags included in the model, both the Akaike and Schwarz Information criteria were utilized. We estimated vector autoregression models, correcting where necessary for autocorrelation in residuals. To test for any causal links between the series, for each pair of M\&A, Granger-causality tests were computed. In Table 4, the results of this analysis are summarized, and statistically significant causalities are marked with asterisks (at 5\% significance level).

Based on the findings, the dynamics of M\&A transactions in the US precedes the dynamics of M\&A in Germany and China; dynamics in Germany precedes that in China and Russia; and in Russia the dynamics of 
M\&A precedes market dynamics in Germany.

This test has some imperfections. The presence of bilateral causal relationship, as in the case of China-Germany, Germany-Russia potentially indicates that there is a third variable that affects the dynamics of the other two series.

Therefore, to obtain more accurate conclusions about the long-run relationship and the behavior of markets M\&A was carried out the Johansen cointegration test. Table 10 below reports the results from both the trace test and the maximum eigenvalue. However, the Johansen test is sensitive to the size of the sample, and we will consider utilizing other methods in the future.

Table 9

Summary of the VEC Granger Causality Test

\begin{tabular}{|c|c|c|c|c|}
\hline Influeces & Recipient & Germany & China & Russia \\
\hline \multirow[t]{2}{*}{$\overline{\text { US }}$} & & $(14)^{* *}$ & $(11)^{* * *}$ & (4) \\
\hline & & US & China & Russia \\
\hline \multirow[t]{2}{*}{ Germany } & & (14) & $(19)^{* *}$ & $+(13)$ \\
\hline & & US & Germany & Russia \\
\hline \multirow[t]{2}{*}{ China } & & (11) & $(19)^{* *}$ & $(11)^{* *}$ \\
\hline & & US & China & Germany \\
\hline Russia & & (4) & (11) & $(13)^{* *}$ \\
\hline
\end{tabular}

Table 10

Johansen Cointegration Test

\begin{tabular}{|c|c|c|c|c|c|}
\hline Hypothesized No. of CE(s) & Eigenvalue & $\begin{array}{l}\text { Max. eigenvalue } \\
\text { statistic }\end{array}$ & $5 \%$ critical value & Trace statistic & $5 \%$ critical value \\
\hline \multicolumn{6}{|l|}{ Russia-Germany } \\
\hline None & . & $31.996^{* *}$ & 14.07 & $37.896^{* *}$ & 15.41 \\
\hline At most 1 & 0.459 & $5.9007 * *$ & 3.76 & $5.9007 * *$ & 3.76 \\
\hline \multicolumn{6}{|l|}{ Russia-USA } \\
\hline None & . & 6.28 & 14.07 & 8.73 & 15.41 \\
\hline At most 1 & 0.097 & 2.45 & 3.76 & 2.45 & 3.76 \\
\hline \multicolumn{6}{|l|}{ Russia-China } \\
\hline None & . & $16.286^{* *}$ & 14.07 & $19.97 * *$ & 15.41 \\
\hline At most 1 & 0.260 & 3.687 & 3.76 & 3.687 & 3.76 \\
\hline \multicolumn{6}{|l|}{ USA-China } \\
\hline None & . & $30.007 * *$ & 14.07 & $36.403 * *$ & 15.41 \\
\hline At most 1 & 0.4263 & 6.396 & 3.76 & 6.396 & 3.76 \\
\hline \multicolumn{6}{|l|}{ Germany-China } \\
\hline None & . & $40.673 * *$ & 14.07 & $48.863 * *$ & 15.41 \\
\hline At most 1 & 0.586 & $8.190 * *$ & 3.76 & $8.190 * *$ & 3.76 \\
\hline \multicolumn{6}{|l|}{ Germany-USA } \\
\hline None & . & $17.817 * *$ & 14.07 & $17.884 * *$ & 15.41 \\
\hline At most 1 & 0.294 & 0.0677 & 3.76 & 0.067 & 3.76 \\
\hline
\end{tabular}

Note. * denotes rejection of the hypothesis at $5 \%$ level.

For the Russia/US series, we cannot reject the null and conclude there is no cointegration between M\&A in these countries. For the Russia/China series and Russia/Germany series, the null hypothesis of no cointegrating vector $(r=0)$ is rejected. Thus, the $M \& A$ in these markets are cointegrated, indicating that there 
is a long-run relationship.

Taking into account that the considered variables are cointegrated, we determined the error correction model that best describes the short-run dynamics. The models were tested for autocorrelation and normality of residuals.

\section{Conclusion}

Activity in the market of mergers and acquisitions is a significant economic indicator. Integration processes play an important role in the financial situations of companies: They can pave the way for company's success, or lead to deterioration of its business standing. In this regard, the development of the M\&A market in Russia requires careful consideration, including through econometric modeling.

We analysed Russian M\&A processes and its components: cross-border transactions and domestic consolidation/ conglomeration deals. For each of the series, we identified the most fitting model to capture the series' temporal behaviour. Results are somewhat consistent across both datasets used, and provide insights into the behaviour of each individual series comprising the aggregate series.

In the Russia-USA pair, our data does not indicate significant causal links in M\&A processes. In the US-China pair, we find evidence for the impact of the US market on the processes in China (second, third, seventh, eighth, ninth, and tenth lag). In the Germany-China pair, China has a long-term influence on the German M\&A market. Between M\&A processes in Russia and China, we find an impact of deals in China (sixth lag) on the Russian market, as well as a long-term influence on the Russian series. The results indicate German M\&A series also have a long-term influence on the Russian series. With future expansion of the dataset, we can expect to have a better ground for further investigating the causal links in M\&A activity.

\section{References}

Barkoulas, J., Baum, C., \& Chakraborty, A. (2001). Waves and persistence in merger and acquisition activity. Economics Letters, 70, 237-243.

Harford, J. (2005). What drives merger waves? Journal of Financial Economics, 77, 529-560.

Ignatishin, Y. (2005). Mergers and acquisitions: Strategy, tactics, finance. SPb: Piter (In Russian).

KPMG Report. (2014). Overview of the Russian M\&A market in 2014 . Retrieved from http://www.kpmg.com/ru/ru/issuesandinsights/articlespublications/pages/ma-survey-report-2014.aspx (In Russian)

Musatova, M. (2011). Empirical analysis of the mergers \& acquisitions dynamics of Russian companies. Vestnik NGU, 11(2), 118-128 (In Russian).

Musatova, M. (2006). Dynamics of mergers and acquisitions in the Russian Federation: Factors, motives, relationships. Novosibirsk: IEIE SBRAS (In Russian).

Polikarpova, M. (2011). Econometric analysis of Russian market of mergers and acquisitions. Prikladnaya Ekonometrika, 4(24), 27-47 (In Russian).

Qiu, L., \& Zhou, W. (2007). Merger waves: A model of endogenous mergers. RAND Journal of Economics, 38(1), $214-226$.

Resende, M. (1999). Wave behavior of mergers and acquisitions in the UK: A sectoral study. Oxford Bulletin of Economics and Statistics, 61(1), 85-94.

Russia - the leader in acquisitions. (2002). Expert, 17, 29 (In Russian).

Shen, C.-H., Chen, S.-W., \& Lin, M.-R. (2008). Common wave behavior for mergers and acquisitions in OECD countries: A unique analysis using new Markova switching panel model approach. Economics Bulletin, 7(8), 1-12.

Town, R. J. (1992). Merger waves and the structure of merger and acquisition time series. Journal of Applied Econometrics, 7 , 83-100.

The role of the state at M\&A market in 2010-2011. (2011). Retrieved from http://mergers.ru/researches/Rol-gosudarstva-na-rynke-sliyanij-i-pogloschenij-2011-31937 (In Russian) 